\title{
The Practice of English Teaching in the Meteorological Correspondence Education
}

\author{
Shaohui Miao \\ Yunnan Meteorological Training Center, Kunming 650034, China \\ Tel: 86-871-4162-709Ｅ-mail: miaoshaohui@sina.com
}

\begin{abstract}
The correspondence education is the important part of the national education, and its education objects give priority to working staffs. The objects of the meteorological correspondence education are working staffs in the meteorological departments, and most of these students have engaged in the operation work for a long time, keeping at a distance with theoretical learning, and because the attended study time of correspondence education is deficient, and most of them are difficult to study. English is a basic course in the meteorological correspondence education, and the students have different English levels, so the English teaching becomes difficult. To enhance the teaching level of the meteorological correspondence education, the existing problems in the current meteorological correspondence English teaching are analyzed, and the methods of adults' English learning are discussed in this article.
\end{abstract}

Keywords: English teaching, Meteorological correspondence education, Practice

In recent years, with the reform and opening up and the continual development of the market economy, as the necessary quality of inter-disciplinary talents, the foreign language ability has been more and more emphasized. "Communicative English" and "Practical English" have been the necessary courses to cultivate talents. In this article, the actuality and problems of the meteorological correspondence English teaching in Yunnan Correspondence Station of the Nanjing University of Information Science \& Technology and the Chengdu University of Information Technology are analyzed, and the countermeasures of the meteorological correspondence English teaching reform are suggested, and the methods of studying English for those adult students in the meteorological departs are discussed to enhance the teaching level of the meteorological correspondence English.

\section{The actuality of English teaching in the meteorological correspondence education}

There have been some problems in the meteorological correspondence English teaching. For example, the teaching is separated with the practice, and though many students have a few years' English learning before the meteorological correspondence education, they still don't understand and say English, and the phenomenon of "Chinese English" can be found everywhere.

Those correspondence students upgrading from technical to undergraduate)have different English bases and lower English level. In these students, many of them only remember hundreds of usual English words, and they have forgotten some basic grammatical knowledge (Dong, 2001, P.47-49), and most students' English base is weak, and the teaching is very difficult because of deficient time and heavy task. At present, many problems exist in many stages such as attended study, tutorship, instruction, homework, and assessment of the meteorological correspondence English. For example, students lack in the motivation of learning are absent in the classroom, and most of them copy homework and treat the examination passively, and keep way from the practice, and the teaching content is old (Chen, 2004).

\subsection{Without teaching outline}

Only by the explanation of English teaching materials and the teaching plan, teachers only obtain a general cognition, and the reference such as the full-time national education and teaching outline is deficient, which would influence the total effect of the teaching.

\subsection{Lagged teaching materials}

For correspondence students, the content of the teaching materials is bald. At present, the teaching materials aiming at the students upgrading from technical to undergraduate are rare, and common undergraduate teaching materials are used. The "Intensive Reading (Book Two and Book Three)"published by the Shanghai Foreign Language Education Press and the "Adult Bachelor's Degree English Examination Guidance" compiled by the Jiangsu Provincial Academic Degree Commission are selected by the Center. Through tens of years, these teaching materials have won wide reputations, but for working staff students, it still seems useless or difficult. Therefore, the content of the teaching material should fully consider the adult students' practice, and it should be different with the 
characteristics of the common higher education emphasizing the theory, and the theoretical part should be sufficient, and the teaching material should emphasize the cultivation of the practical skills and the innovational ability, and strengthen the combination of theory and practice. The teaching materials should avoid following the popular, and ignore adult students' practice, and blindly use the common college materials, which could not achieve normal teaching effect (Chen, 2008), but bring large difficulties for teachers to organize the teaching.

\subsection{Teaching objects'levels are different}

Most meteorological correspondence students belong to the working staffs of the meteorological departments, and they play multiple roles in the society and family, and their burdens of work and life are very heavy, and most of them are old, and part students only have weak cultural base, and the conflict between working and learning is very obvious, and most students generally lack in study time. In the same class, students' ages are largely different even fro 20 years old, and husband and wife, and aunts and nephews or nieces are in the same class, and their abilities to accept knowledge are different. And many of them are the chief of county meteorological administration. For example, there were 36 students in the atmospheric science specialty correspondence undergraduate class of Nanjing University of Information Science \& Technology of 2005, and about 20 of them are cadres above the section chief, and most of then could not ensure the attended study time.

\subsection{Teaching time is deficient, and the arrangement is not reasonable}

The instruction teaching time of the college English course is deficient, and in each term there are 22 class hours for one book, and then the university will organize the examination. There are former three terms in each grade to arrange the course of English, but the content of three books should be taught, and thus quick teaching is hard to ensure the teaching effect. In such short time, students are difficult to grasp certain glossary, know the characteristics of the grammatical structure, and complete three books, and in the latter one and half years, they will not use English, so when they graduate, the English knowledge they have learned would return to the teacher.

1.5 "Examination-oriented education" lacks in the cultivation of language communicative ability, and most students almost have not listening and oral ability

Most students possess a few words, and the students who know hundreds of words are excellent, and some students only know "Hello!" and "Bye-bye!" and some students even don't know how many letters there are in English, not to say nothing of the phonetic symbols, and for them, English words know them, but they know few English words. For a long time, most teachers adopt the traditional teaching methods. Taking teachers as the center, traditional teaching methods only emphasize the explanation and instruction of knowledge, and this method has deep cultural meaning and active factor, and it could strengthen the phrasing base, but it costs time and has low efficiency, and ignores the special practice of the English course (Sun, 2005).

\subsection{The teaching means is single and lagged}

One chalk, one blackboard, one textbook, and face-to-face oral and writing instruction, are difficult to stimulate students' learning interests.

\section{Main causes of these problems}

\subsection{Disadvantages existing in traditional education mode}

In China, both teachers and teaching materials are the symbol of authority, in the leading state. Teachers' responsibility is the infusion of knowledge, and students are usually accepted passively. Because of the limitation of the meteorological correspondence education, students have deficient learning time, and the content of the textbook is conflict with the practical instruction time, so students have not sufficient training opportunities and can not creatively use the learned language.

\subsection{Students' enthusiasm of studying English could not be stimulated}

Most meteorological correspondence students always put their learning interests on the specialty course of meteorology, and the learning of language is useless for them, and they feel that the learning of English is rare in the working and life, and some students even could not use one English word in their lives. But the English learning needs more listening, reading, and speaking, because students' learning attitude is not right, which is another important factor to impact the teaching of English.

\section{Countermeasures of the meteorological correspondence English teaching reform}

\subsection{Strengthening the innovational consciousness}

In the day that the international communication is increasingly frequent, and the opening up to the outside world is more extensive, so the feasible meteorological correspondence English teaching outline must be constituted. In the 
curriculum provision, the listening, the oral English, and the writing should be added, and these courses should be scientifically arranged in to the whole process of the correspondence learning of three years.

\subsection{Strengthening the quality education}

In the teaching, not only the instruction of language knowledge, but also the cultivation of the language utilization ability should be emphasized, and both the theoretical knowledge and the practical ability should be emphasized at the same time.

\subsection{Combining the language learning with the western culture}

In the teaching, some content about the culture should be introduced intentionally, and combining with the relative background knowledge of the textbook, students will understand the textbook more exactly and profoundly, and be more interesting in the learning of English.

\subsection{Improving the teaching method}

Psychological glossology thinks that students' interior factor will decide the quality of education. To turn students' "passively accepting" to the "actively learning", the teacher-oriented classroom practice should be turned to students' orientated. At the same time, many modernization teaching means such as language laboratory, computer, and multimedia equipment should be utilized to build the atmosphere to help students study the language, and enhance students' English listening, oral level, and cultivate their English sense (Sun, 2005). To cultivate the talents with English reading and communicative ability is the responsibility and task of the correspondence English, and the past teaching mode should be reformed, and in the teaching, the quality education should be strengthened in the reform and exploring.

\section{Approaches to enhance the meteorological correspondence English teaching level}

\subsection{Enhancing the practicability of the content of the meteorological correspondence English}

The meteorological correspondence English teaching should be different with that of the full-time national education. The instructed students are adults, so according to the practice, teachers should teach more practical English and oral exercises, such as everyday English, teachers don't only explain the grammatical structure, glossary, reading comprehension, and translation, as in middle schools. Being different with middle school students and college students, the students in the meteorological correspondence class have not the pressure of the college entrance exam, and the pressure of CET. Therefore, aiming at this special group, the listening, the oral English, and the practical language should be strengthened, not only the knowledge about the exam.

\subsection{Enhancing the interaction in the classroom between teachers and students}

Teachers should correct their positions, and give priority to students' exercises of listening and speaking, instead of cramming method of teaching, and especially for English, more speaking and exercises could enhance the oral level, so teachers have to distinguish the primary and the secondary, and students could train their spoken English in the limited instruction time.

\subsection{Stimulating students' interests and developing abundant and colorful class teaching}

The interest in the teaching is very important. According to the content of the teaching materials, the characteristics of the course, and the students' age structure, teachers should utilize optimal methods to stimulate students' interests and learning enthusiasm, and achieve the optimal effect of the class teaching. Teachers should devote love, prepare for lessons carefully, and make all students to always keep the active learning attitude. Students should divide students into different groups to train English each other, sing English songs, speak English story, and organize activities after school, and in this way, the optimal effect could be achieved.

\subsection{Applying modernized computer and multimedia network technology in the meteorological correspondence English teaching}

Teachers should fully use advanced information technologies, and push the English software teaching based on computer and network, and provide good language learning environment and condition for students. The multimedia technology is to blend words, data, photo, stereo, and dynamic video frequency together by the comprehensive interactive function of the computer. By the multimedia technology, students' eyes and ears should be stimulated by many effects such as voice and picture, so the learning impression could be deepened, and in this way, the teaching of English could get twice the result with half the effort.

English is a basic course of the meteorological correspondence teaching, and it has important function to cultivate new inter-disciplinary talents for the meteorological department. Someone said that "English is not learned but taught", which indicates the nature of English learning, and reflects students' status and roles in the English learning. 
Teaching could help students to make clear the learning direction and grasp the emphases of learning, and studying would directly influence the teaching effect, and both of them should be promoted and should not be replaced each other.

\section{References}

Chen, Jinzhong. (2008). Multimedia Computer Assisted College English Instruction for Reeducated Undergraduates Challenges and Countermeasures. Continue Education Research. No. 5.

Chen, Xiang. (2004). Main Problems and Improved Countermeasures in Higher Normal Correspondence Education. [Online] Available: http://cpfd.cnki.com.cn/Article/CPFDTOTAL-ZGCN200412001124.htm (Dec 1, 2004).

Dong, Peipei. (2001). Problems and Countermeasures of College English Teaching in Correspondence Education. Journal of Ningbo Institute of Education. No. 2. P.47-49.

Sun, Qin. (2005). Actuality and Teaching Reform Countermeasure of Party School Correspondence English Teaching. [Online] Available: http://news.sohu.com/20050404/n225015954.shtml. (April 4, 2005). 